\title{
Retraction Note: CD14 Promoter-159 Polymorphism Is Associated with Reduced Risk of Intestinal-Type Gastric Cancer in a Japanese Population
}

Tomomitsu Tahara $\cdot$ Tomoyuki Shibata $\cdot$

Ichiro Hirata $\cdot$ Hiroshi Nakano $\cdot$ Tomiyasu Arisawa

Published online: 18 August 2012

(C) Springer Science+Business Media, LLC 2012

\section{Retraction to: Dig Dis Sci (2009) 54:1508-1512}

DOI 10.1007/s10620-009-0793-5

The article, CD14 promoter-159 polymorphism is associated with reduced risk of intestinal-type gastric cancer in a Japanese population published in Digestive Diseases and Sciences, Volume 54, Number 7, 2009, pp. 1508-12 has been retracted due to duplicate publication. The data set presented in the article was previously published in the journal article Association of polymorphism of TLR4 and CD14 genes with gastroduodenal diseases in Japan, Inflammopharmacology Volume 15, Number 3 (2007), 124-128.

The online version of the original article can be found under doi: 10.1007/s10620-009-0793-5.

T. Tahara $(\bowtie) \cdot$ T. Shibata $\cdot$ I. Hirata $\cdot$ H. Nakano Department of Gastroenterology, Fujita Health University School of Medicine, 1-98 Dengakugakubo, Kutsukake-cho,

Toyoake, Aichi 470-1192, Japan

e-mail: tomomiccyu@yahoo.co.jp

T. Arisawa

Department of Gastroenterology, Kanazawa Medical University, 1-1 Daigaku, Uchinadamachi, Kahokugun, Ishikawa 920-0293,

Japan 